\title{
Towards a More Realistic Depiction of the Earth's Surface on Maps
}

\author{
JaCeK Drachal $^{1}$ and Anna Dębowska ${ }^{1}$
}

\begin{abstract}
In 2000, the shuttle radar topography mission (SRTM) produced the most complete, highest resolution digital elevation model (DEM) of the Earth. These data were used to create global $3^{\prime \prime}$ DEM and to correct $30^{\prime \prime}$ DEM which are both available on the internet. After a careful survey in the Institute of Geodesy and Cartography, Poland, these elevation data were recognized as extremely valuable and worth developing a unique form of visualization. As a result, a new design of a physical map of Europe at scale of 1:10 million was developed. For depicting the shape of the terrain, an original modification of combined shaded relief was employed, to reveal all the nuances of elevation data. True colors of the Earth's surface represented on the map originated from MODIS satellite image. The combination of true colors and terrain features made a realistic map, showing the landscapes as if from a point above the Earth. The image of the terrain is extremely detailed as it is based on the abundance of data defining the elevation of each point of land.
\end{abstract}

Key words: Map, reference, GIS, DTM, MODIS, SRTM.

\section{Introduction}

Small scale general maps are the most popular. They show the world, continents or big countries in a way that is easy perceivable. The landmasses are pictured against oceans and the maps are filled with the basic spatial information: shape of the terrain, land cover, hydrography, settlement network, roads and borders. Such maps being a simple model of the world around us and serving as a spatial reference, are useful tools in many applications. In history general maps evolved each time a significant improvement was made in the area of measurement techniques. Triangulation surveys initiated in greater scale in the eighteenth century led to tracing real

1 Institute of Geodesy and Cartography, Modzelewskiego 27, Warsaw, Poland. E-mail: jacek.drachal@igik.edu.pl; anna.debowska@igik.edu.pl outlines of continents and barometric measurements made in the nineteenth century gave a substantial number of height readings. Based on the new data, better maps could be compiled, which often required new methods.

It was the case when a great amount of elevation data became available and they could be used in a more accurate depicting of the mountains. After trials with hachures and contours, a method based on hypsometric tinting was finally accepted and it appeared to be extremely successful. In this method, a set of selected contour lines is drawn in the land area, cutting it into several elevation zones. These zones are colored in accordance with a carefully designed color scale to make a 3D impression. The assignment of green to lowlands and brown to highlands proposed by Emil von Sydow in the mid nineteenth century on the map of Asia, survives to this day as a general standard, although particular solutions vary in shades of these two colors and their corresponding intervals of elevation. These most popular general maps customarily named physical, for over 100 years used to be recognizable by their characteristic colors: green-brown lands and blue waters.

The situation is changing under the influence of new measurements and surveys made with the use of satellite techniques. Good examples are true color images of the Earth's surface which are also bluegreen-brown but the meaning of colors is different, they are the actual colors of the Earth viewed from space. These images are so popular that the physical map colors ceased to be read correctly (PATTERSON and JENNy 2011). Such a situation is a challenge for cartographers who try to find a solution. The general idea is to abandon the abstract hypsometric tints and to represent the land on maps more or less in accordance with the reality known from satellite images. 
For that purpose true color images of the Earth are used, or realistically colored images of land cover derived from multispectral satellite imagery classification. Real image elements are woven into the cartographic image, and drawing techniques mimic a photograph (PAtTERSON 2002). The shape of the terrain representing an equally important element of the natural landscape is then shown with the use of shaded relief.

The idea of combining shaded relief with ground and vegetation colors is not new. It was an important issue for American cartographer, Hal Shelton (1916-2004) when he was making orientation maps for airline passengers (Iмноғ 1982). He used to represent the world on maps in a very realistic manner. A good example is the New Europe map at a scale of 1:5 million from 1968, showing the author's intuition of the actual colors of the Earth's surface recorded 30 years later by MODIS (JenNY and RABE 2006). One more reason to think about a new depiction of the Earth's surface is the elevation data file of unprecedented detail which was recently collected from a satellite level during the shuttle radar topography mission (SRTM) (FARR 2007). Such data can not be fully appreciated on a hypsometric tinting map because of its principle which is to simplify data and make contour shapes regular. The only solution for displaying these valuable data is to apply shaded relief.

For a long time, shaded relief on maps could be produced only by expert cartographers as the work was so complex and laborious. Fortunately, in the age of computers, this method is undergoing a renaissance being created analytically from digital elevation models (DEMs) (JENNY and RABE 2006). Beside the simple version of the method there are its modifications. They are based on combining two types of the shading effect induced by different positions of the light source: oblique shading and slope shading (KenNelly 2008), (PAtTerson and Hermann 2004). In combined shading the principle of depicting slopes: "the steeper, the darker" is preserved together with the 3D effect property of oblique shading (Iмноғ 1982).

The new representation of the Earth's surface on a reference map can be very useful in geophysical research for which the correctly depicted object of study that is the Earth, is important. It can be particularly useful if due care is taken in depicting the topography, because the knowledge of the shape of the Earth's surface is fundamental in modern geosciences. It is simply a dominant controlling factor in natural processes that occur on the ground, in the atmosphere and lithosphere (CRIPPEN 2010). Without exaggerating the importance of small scale reference maps for geophysical research, which is limited to a rather preliminary stage and general considerations, it is clear that even such maps can be useful in this field. Mere depiction of the Earth's surface in an innovative way can be inspiring and can stimulate the imagination to consider phenomena and processes.

A realistic depiction of the topography is exactly the main concern of authors of this paper which describes works on a new general reference map of Europe at scale 1:10 million. The works focus on pictorial representation of the terrain modeled based on detailed satellite measurements of SRTM. For modeling the terrain an original modification of shaded relief is employed. It is a combined shaded relief with parameters experimentally determined in a way so as to reveal all the nuances of satellite elevation data. The method is not using simplifications or generalizations, typical for maps with hypsometric tinting. The shaded relief image of the terrain is painted in the true colors of the Earth in accordance with the MODIS satellite image. MODIS images show ranges of vegetation and dry areas and, thus, indirectly inform about the water cycle, which is also of interest in geophysics. Placing on the map two basic elements making up the landscape not only provides a valuable picture in terms of information but also a realistic picture, which as it turns out, is important because realistic means of expression are advantageous over the abstract ones in making maps (PATterson 2002).

\section{Source Data}

To describe the Earth's topography analytically, DEMs are used which are conventionally derived from topographic maps. However, a globally consistent topographic data set can only be produced by employing a globally consistent mapping technique (FARR 2007). 
Such technique was demonstrated in 2000 , by the SRTM (BAMLER 1999). There are essentially three types of SRTM elevation data. The names of each of the subtypes are distinguished by a number. SRTM1 is a $1 \mathrm{~s}$ terrain model (data at intervals of every $30 \mathrm{~m}$ ), which is available only for the United States. The three second model-SRTM3 - is a collection of elevation data at intervals of every $100 \mathrm{~m}$ (MichalaK 2003). In the SRTM30 model the elevation readings are made at intervals of every $30 \mathrm{~s}$ (which is about $1 \mathrm{~km}$ ). The last two sets are publicly available in the internet.

The SRTM3 collection is regarded as global, because it ranges between the parallels of $55^{\circ} \mathrm{S}$ and $60^{\circ} \mathrm{N}$, thus covering most of the Earth's land area excluding Antarctica. The collection of this data was made within 11 days of February 2000, when the space shuttle Endeavour realized its mission. The exceptional value of SRTM3 is due to great geographical coverage, consistency and detail. This 3-s collection is based on the original 1-s terrain model (GuTH 2006). When the SRTM data set was created, there already existed a less detailed model GTOPO30, which was developed primarily on the basis of maps (detail of $30 \mathrm{~s}$ or $1 \mathrm{~km}$ ). SRTM30 is somehow a new version of the $1 \mathrm{~km}$ model, which has been developed based on satellite data.

To assess data quality the terrain models SRTM3 and SRTM30 were examined. Shaded relief images generated from SRTM3 data were compared with the image based on elevation data obtained from the 1:200,000 map (Fig. 1). The data available covered the Lake of Galilee. It was noted that the SRTM3 model was at least as detailed as the digital terrain model (DTM) from the map, and in some places was even more specific (the valley of the Jordan, the Mediterranean coast).

In the next trial, the $1 \mathrm{~km}$ data of GTOPO30 and SRTM30 was used to create shaded relief maps and to compare them (Fig. 2). In the old version of the $1 \mathrm{~km}$ model (GTOPO30), the traces of map sheet edges are visible in flat areas (bottom right corner). The new version SRTM30 is free of these errors.

According to the theoretical assumptions, an image for visualization at a scale of 1:10 million should have a ground resolution of about $1 \mathrm{~km}$ and, thus, the terrain model SRTM30 together with the $1 \mathrm{~km}$ version of the MODIS imagery are sufficient for the purpose. A shaded relief image of SRTM30 elevation data was created with the software named Surfer. The parameters of the image, affecting its brightness and contrast are: the elevation angle of the simulated illumination over the horizon $(H)$ given in degrees and the vertical scale factor $(Z)$ given as a real number. The appearance of the shaded relief image is affected also by the illumination's azimuth, but this in cartography is traditionally set to the north western direction.

MODIS, which is short for moderate resolution imaging spectroradiometer, is an imaging device owned by the National Aeronautics and Space Administration (NASA). It was designed to observe the land, oceans and atmosphere of the Earth. MODIS
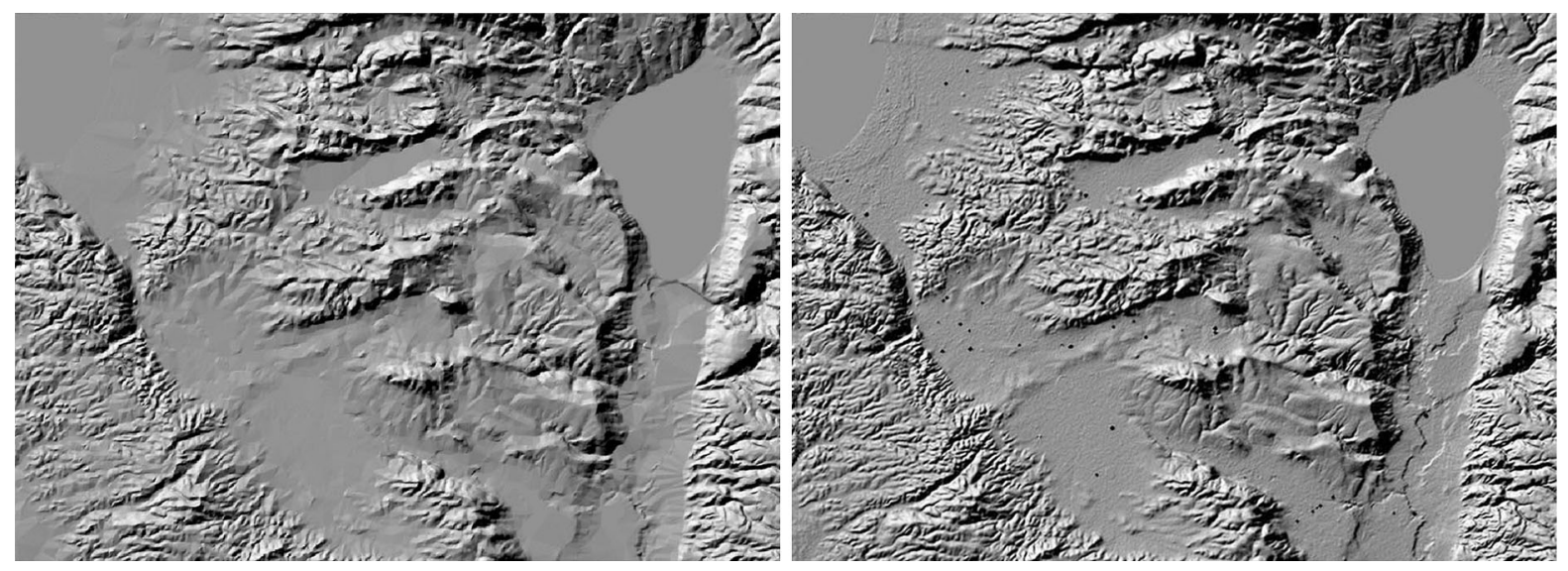

Figure 1

Digital elevation models based on: a map 1:200,000 (left) and SRTM3 (right) 



Figure 2

Comparison of elevation data: GTOPO30 (left) and SRTM30 (right)

has been installed on two of the satellites orbiting the Earth: Terra in 1999 and Aqua in 2002. These satellites are placed in orbit about $705 \mathrm{~km}$ away from the Earth's surface. They record the image of the planet in 36 ranges of electromagnetic radiation, with wavelength range from $0.49-14.38 \mu$. The images in natural colors (true colors) are freely available on the internet as single images taken on a particular day, or as compositions based on longer observations. These compositions are free of clouds and radiometric defects. Their ground resolution is $250 \mathrm{~m}$ for the red band and $500 \mathrm{~m}$ for the green and blue.

MODIS imagery selected for the map of Europe comes from the collection of monthly observations made for 2004. Its name: world.200408.3×21 600x21600.C1.png means fragment C1 from August 2004, with the greatest detail available, i.e., $500 \mathrm{~m}$ ground resolution, structure RGB and size 21,600 lines by 21,600 pixels. For the use at a scale of 1:10 million, the image was diminished twice with bilinear interpolation, used for resampling.

\section{Theoretical Basis}

The intended map was assumed to be a specific form of scientific visualization (MEDYŃsKA-GuliJ 2011), however, this was not addressed only for scientists. It was also directed to the average reader as a tool for shaping their imagination about the world around them. The aim was to show the data, in our opinion, extremely valuable, in a form that everyone can analyze in their own way. Our role was to make them available in a form that at the same time you can see the terrain and vegetation (in varying intensity). These are the two main factors shaping the landscape, so you can try to imagine the scenery.

A synthetic image usually allows you to see something that was not noticed when observing each of the components separately, and, therefore, such variant of data visualization was adopted. A picture of the terrain must be supplemented by a cartographic grid and points or lines of reference such as cities or rivers, because the visualization of geographic data becomes clear only when it takes the form of a map. The shaded relief image is used as a way to visualize the SRTM elevation data and the RGB image structure as a natural form of MODIS data visualization.

Shaded relief images are created according to Lambert's law, i.e., the brightness of the illuminated surface is the greatest when the surface is facing the light source (the angle of incidence between surface normal and the direction of radiation is zero) and decreases to smaller value, when the area is deflected from the light source at some angle different from zero. The dependence between this angle and the brightness of the illuminated surface is the cosine.

Within the accuracy of the proportionality factor, it describes the brightness of each pixel of the shaded relief image. The position of the elementary surface in relation to the light source is expressed by the size of the angle of incidence calculated based on the DTM for the selected height and azimuth of 
the simulated illumination. When the height parameter is set to $90^{\circ}$ we are dealing with vertical illumination and so called slope shading. For other values of the height parameter customarily set to $45^{\circ}$, so called oblique shading takes place.

Scientific visualization of imagery data with the use of RGB image structure has long been used in remote sensing, and a classic example is called the "false color composite" (FCC). FCC is the image having a structure of the RGB digital color image, which is formed artificially from three monochrome images of the same area recorded in the spectral bands: green, red and infrared. The prominent feature of such composites was the red color of the vegetation. Thanks to this technique, three monochrome images recorded over the area from high altitude could be analyzed simultaneously.

When it was noted that different ground resolution can be used in the visualization of image data, and the resulting synthetic image retains the physical sense, this observation was used to improve the high-resolution satellite images (first time in Ikonos images in 1999).

It turned out that in order to gain the high ground resolution of RGB color images, such as $1 \mathrm{~m}$, it is enough to provide the system with a wide band panchromatic recorder of this resolution, and the narrow range sensors of R, G, B may have the resolution even four times lower. Then, to obtain a color image with a resolution of $1 \mathrm{~m}$, it is sufficient to replace the original intensity channel within the IHS structure (intensity, hue, saturation) by a registered independently panchromatic image. To convert the digital RGB image to the IHS structure and back, a special software is used (Drachal 1994).

At a scale of 1:10 million, it is sufficient to keep image details on the level of $1 \mathrm{~km}$. This is the original resolution of the SRTM30 relief map and twotimes lowered resolution of MODIS imagery. The synthetic image may be interpreted as a naturally colored relief map or as the image of the Earth's surface with highlighted relief. For the developed series of maps, the procedure applied to the map at a scale of 1:10 million was a special case when the resolution of both types of data was equal. For maps at other scales, this relation was different from 1:1 and adopted values of 2:5 and 1:5.
To create a synthetic image of the assumed characteristics, it is usually not enough to replace one image component by another. During the research, a series of mathematical operations is used to achieve the result that retains the essence of the information contained in the data. These operations are ones that highlight desired features without introducing distortions (Drachal 1987). And so, for example, a mathematical transformation of the image consisting in changing the numbers encoding pixels is acceptable if the change is monotonous throughout the range of numbers $(0,255)$. It follows that the application of mathematical operations such as summation, multiplication, or division on the images treated as numeric arrays is admissible.

In this project, the research consisted of putting the images of the same area one over another, and creating a "sum" by using one of the predefined functions: opacity, multiplication, overlay or screen. Several such operations gave the wanted result. The options were evaluated visually on the screen. The method of visually assessing image variants composed by using preset functions is very effective. It allows you to immediately select the right option, or reject the wrong one, in approaching the target which satisfies the assumptions. In the selection, the criterion was the maximum diversity of colors, but not in the image as a whole - only in each of its parts. The aim was to create an integrated image instead of artificially colored shaded relief. The second aim was to extract possible areas of similar visual characteristics that might indicate the presence of distinctive areas in a real landscape.

Software functions used for creating synthetic images come from Photoshop software where their definition is as follows. Opacity is used to add images. In general, when two images of the same area are placed one over another, and the foreground image is made to some extent transparent, the sum $C$ of the background pixel $A$ and the foreground pixel $B$ with the opacity pexpressed as a value between 0 and 1, is defined as:

$$
C=A+p(B-A) .
$$

Gray tones of pixels $A, B, C$ should be understood as their codes on the digital tonal scale $<0-255>$, or single color pixel coordinates in the 
color image. If the color of the transparent pixel (opacity $p$ ) is the same as the background, the pixel in the background remains unchanged. If the pixel with a new color is not transparent, then only its color is visible as a sum. The opacity function can be used with other functions, thus, significantly increasing their effectiveness.

Overlay is essentially a contrast enhancement tool. When one image is placed over another and the overlay function is active, the visible result has particular characteristics. For dark tones of the foreground image (overlay), i.e., for codes where $A<128$ and for any background code $B$ the effect is the following:

$$
C=\frac{2 B A}{255}
$$

where $C$ symbolizes tonal codes of the resulting image. For bright tones of the overlay, i.e., for codes where $A>127$ the effect is the following:

$$
C=255-\frac{2(255-B)(255-A)}{255} \text {. }
$$

The overlay function causes the non-linear contrast enhancement in the resulting image, whereby the result is tonally closer to the image used as the overlay. This means that changing the order of the components in this function results in a result of different contrast.

"Screen" brightens the image and reduces its contrast according to the formula:

$$
C=255-\frac{(255-B)(255-A)}{255} .
$$

"Multiply" darkens the image and reduces its contrast according to the formula:

$$
C=\frac{A B}{255} \text {. }
$$

\section{Procedure of Merging Images}

Analyzing the meaning of the parameters, a series of shaded relief images was created for different values of $Z$ and $H$. They are summarized as an array for comparison, as shown in Fig. 3. Parameter $Z$ changes in the vertical direction, from the value of $Z=0.00001$ at the top, by the $Z=0.00005$ in the middle row to $Z=0.00010$ at the bottom. In the horizontal direction, from left to right, there are changes of the elevation angle of the simulated illumination $H$ from $30^{\circ}$ by $45-60^{\circ}$.

Based on experience, two images were selected for further trials because of their moderate contrast: one with the elevation angle of the simulated illumination $H=30^{\circ}$ and the vertical scale $Z=0.00001$ and the other with $Z=0.00005$. This characteristic increases the capability of synthesis with other images without fear of going beyond the scale of the codes. After making simple synthesis with a color MODIS imagery, it was noted that the simple application of one function will not be sufficient.

The trial included summation of MODIS imagery and shaded relief image, overlaying of shaded relief image with MODIS imagery and the replacement by a shaded relief image, of the intensity component of MODIS imagery converted to IHS structure. None of the three synthetic images were accepted as the appropriate form of visualization, because a poor three-dimensional effect was gained at the expense of a significant reduction in color scale compared to the original MODIS imagery.

It was noted that a procedure consisting of a number of operations offers better opportunities in merging images. The best result is presented in Fig. 4. On the left, there is a whole image used for trials, and a small fragment in full detail on the right. The procedure includes multiplication of a shaded relief image by MODIS imagery ("multiply" function), and then screening the result by its copy ("screen" function).

The resulting synthetic image was satisfactory, however, a possibility of other solutions was checked. Once again, an array of shaded relief images from Fig. 3 was examined. In the bottom row, in the images created for $45^{\circ}$ and $60^{\circ}$, a qualitative difference in depicting mountains was noticed (despite the difference in brightness). Again, the impact of the elevation angle of the simulated illumination $(H)$ on the image was analyzed. It turned out, as shown in Fig. $5 \mathrm{~b}$, that the image brightens with the increase of the elevation angle of the simulated illumination, and only the most oblique slopes of the mountains remain dark. Steeply inclined slopes are darker on the south east side, but also on the illuminated side they are 




Figure 3

Shaded relief images for three values of $Z$ (from top) $0.00001,0.00005,0.00010$ and three values of $H$ (from left) $30^{\circ}, 45^{\circ}, 60^{\circ}$


Figure 4

Result of the two-step procedure of merging MODIS image with shaded relief (details in the text above)

darker than the flat areas. Then, a shaded relief image for $H=90^{\circ}$ was made and examined. It turned out that the mountains are depicted in dark tones, with no relation to any direction, while the ridges and valleys are marked with bright lines (Fig. 5c).
Subsequent trials with shaded relief image of $H=90^{\circ}$ led to, as it turned out later, valuable additional images, used for the modeling of the terrain image. At the fivefold magnified parameter $Z$, the area of dark tones increased, and the image had more 



Figure 5

Comparison of shaded relief images created for different elevation angles $H$ of the simulated illumination. The angels are: $30^{\circ}(\mathbf{a}), 75^{\circ}(\mathbf{b})$, $90^{\circ}(\mathbf{c})$
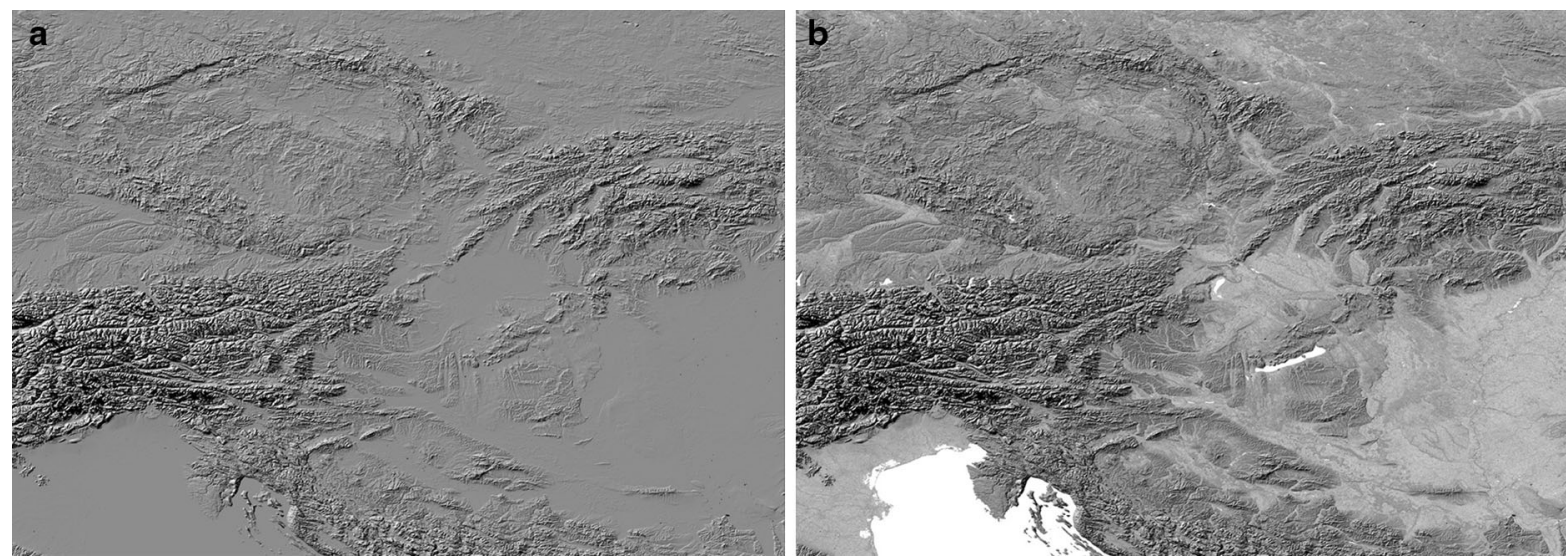

Figure 6

Comparison of the shaded relief images: a a simple model H30, b mixed model $\mathrm{H} 30 \mathrm{H} 90$

contrast, with no intermedia,,te tones, clearly separating the flat and sloping areas.

Having these additional black and white images made it possible to make a new synthesis with the color image. But first the attempt was made to convert them into one image. After a series of trials with various functions and various $Z$ parameters of the $90^{\circ}$ model, it was noted that this model for $Z=0.0005$ connected by screen function with the $30^{\circ}$ model results in a picture of new quality (Fig. 6b). It shows a clearly visible difference between the darker mountainous areas and brighter areas where the slope is very low.

Brightening of flat areas revealed small height differences, including outlines of river valleys, which are invisible on ordinary models. In this way, the ordinary shaded relief model has been enhanced with a delicate drawing of the hydrographic network. As a result, the typical model exposing only mountains, has been converted to a more realistic picture of the area marked with the situation, also on flat areas.

In the modified model, the so-called combined shading, the scale of tones ceased to play a clear-cut role in the model as usual, i.e., such that the bright tones mean slopes on the lit side, the dark tones, slopes on the unlit side and the intermediate tones mean no slope areas. In this new model, the light and dark tones in the same way depict mountains, but the light tones are also used to symbolize no slope areas. In addition, in gray tone are drawn scarps and edges 
of the valleys, invisible in the ordinary model. Interestingly, because of the modification introduced, the model does not lose its visuality and, in fact, becomes more demonstrative, as the picture of the terrain. Probably, our perception of the absolute brightness of the tone is less important than the local relationships between light and dark parts of an image.

If shaded relief technique is regarded as a way of scientific data visualization, then we may admit that this mixed model accomplishes the function even better then the ordinary model does. It shows detailed data on flat areas and just there this new type of data (SRTM) showed its value giving a homogeneous terrain model on large areas where maps usually had the biggest mistakes.

The mixed model 3090 (Fig. 6b) was analyzed to explain how the combination of the two models gives such results. In the range of slope values between $0^{\circ}$ and $90^{\circ}$, the value of the angle of incidence is equal to the slope, because normal to the surface coincides with the direction of the rays. In the H90 model, the cosine dependence reaches a maximum (whiteness in the image) for the slope equal to zero $[\cos (0)=1]$, then drops slightly for slopes equal to $30^{\circ}(0.87)$ and drops to half for slopes equal to $60^{\circ}$ (intermediate gray in the image). The rest of the image is left for dark gray tones.

Based on the same data model, by increasing vertical exaggeration (parameter $Z$ ), larger values of slopes can be calculated, thus affecting the appearance of a shaded relief model. In extreme cases, you can change the entire range of slopes greater than $20^{\circ}$ for example, into slopes of extremely large values of $80-90^{\circ}$, and then the model will be nearly black in hill-filled areas. Such models were obtained in a series of trials, and a model with parameter $Z=0.0005$ was used for the merge presented in Fig. 7b. Large values of $Z$ do not affect only the perfectly flat areas, with a slope equal to 0 , while the areas of minimum slope are exaggerated. These small changes of the plain surface are well exposed in the model H90 with high $Z$.

The second component of the merge is a normal H30 model. At the same range of slope values, the function (1) graph for this model is shifted to the right by $60^{\circ}$ with respect to the graph of $\mathrm{H} 90$ so that the function reaches a maximum for the slope of $60^{\circ}$. It begins, however, from the mean value of 0.5 for the zero slope (flat areas as intermediate gray in the image), and has values close to 1 for slopes of 30 by 60-90 (bright tones).

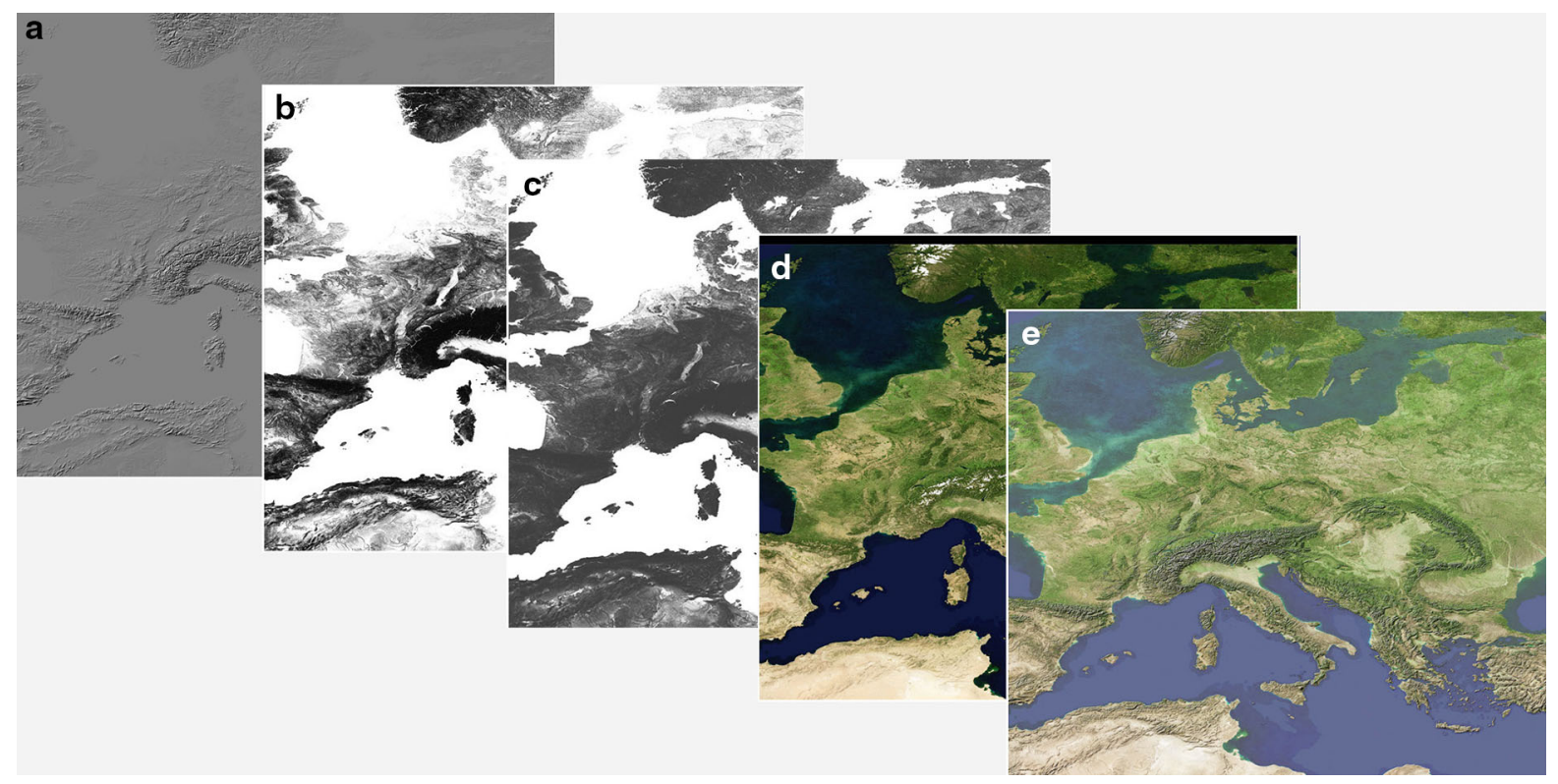

Figure 7

Input images: a shaded relief $\mathrm{H} 30, \mathbf{b}$ shaded relief $\mathrm{H} 90, \mathrm{Z}=0.0005$, $\mathbf{c}$ shaded relief $\mathrm{H} 90, \mathrm{Z}=0.001$, d MODIS imagery and the result e 


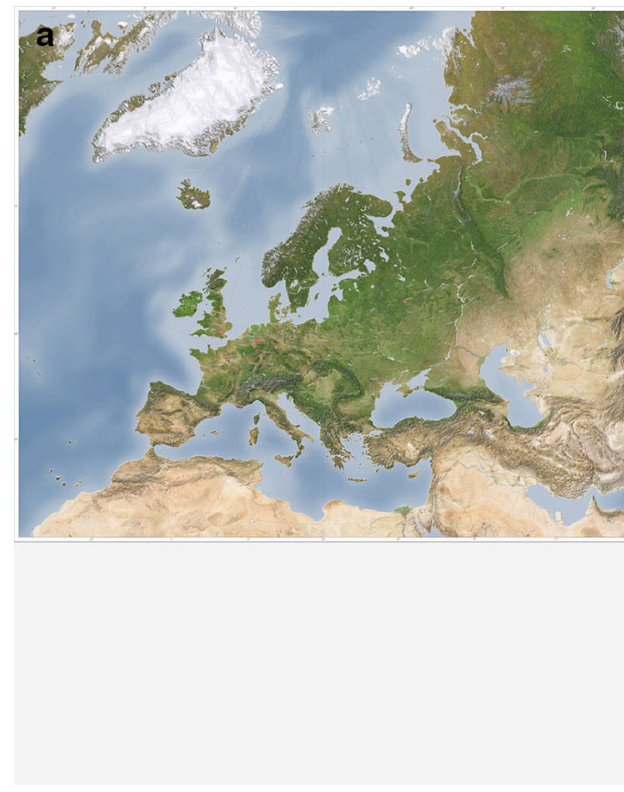

The final version of the map of Europe at a scale of 1:10 million in the azimuthal projection: the whole map in miniature (left), fragment in full detail (right)

According to the screen function formula, when mixing images of $\mathrm{H} 30$ and $\mathrm{H} 90$, the only areas unchanged in the $\mathrm{H} 30$ model were these which went on very dark tones in model H90 (mountainous areas). Other areas of the $\mathrm{H} 30$ model, met bright tones in model $\mathrm{H} 90$ and were considerably lightened.

Base information on producing combined shading from slope shading (H90 here) and oblique hill shading (H30 here) is contained in Imhof's 'cartographic relief presentation' (IMHOF 1982). Some variants of combined shading made with computer software are mentioned by Patterson/Hermann and Kennelly (2008).

After examining the possibilities and advantages of merging shaded relief models of different parameter $H$, new attempts were made to synthesize them with the color MODIS imagery. The following four images were selected for trials:

1. Shaded relief model (H30) created for the elevation angle of the simulated illumination $H=30^{\circ}$, azimuth NW and the coefficient $Z=0.00005$ (Fig. 7a).

2. Shaded relief model (H90) created for the elevation angle of the simulated illumination $H=90^{\circ}$, azimuth NW and the coefficient $Z=0.0005$ (Fig. 7b).
3. Shaded relief model (H90) created for the elevation angle of the simulated illumination $H=90^{\circ}$, azimuth NW and the coefficient $Z=0.0010$ (Fig. 7c).

\section{MODIS imagery (Fig. 7d).}

The best procedure gave the result presented in Fig. 7e. It included following steps: The black-white images [1] and [2] were merged with the use of the "multiply" function in a proportion of 67 to $33 \%$. The result was overlaid (function "overlay") with MODIS imagery [4]. This new result was added twice to image [3] in a proportion of 60 to $40 \%$ (function opacity). The result was accepted because it met the imposed demands. It looked integrated and displayed advantages of both sources of data: wide range of colors and sharp detail. Areas of homogenous visual characteristic were also clearly visible.

\section{Cartographic Layout}

Visualization of the elevation data would be illegible without reference elements or would be hardly visible if there was too many such elements. Therefore, certain quantitative and qualitative 
restrictions are advisable in designing the cartographic layout for this kind of visualization. The designing process was in our case associated with making many trials, estimations and decisions, both in terms of selection of possible items and the determination of their graphic form. The choice of, e.g., color, line thickness and style, was preceded by estimation of the item printed by a high-quality printer. In this experimental design, we could confirm some general cartographic rules and get some new experience. Certain remarks are worth mentioning.

Among reference elements, water bodies make a background for any depiction of the land and their contrast with the land is basic in the map (KeAtes 1973). The unsaturated colors seem to be more appropriate to present large surfaces, and saturated colors inversely, the small spaces. Rivers are not only a very important part of the landscape, they also act as orienting features (often in relation to rivers other elements are recognized).

Another orienting element is the settlement network. According to the assumed graphical model, selected cities are presented as red polygons symbolizing the built-up areas. They are capital cities and cities with important functions. Such arrangement allows the map reader not only to learn the location of the city, but also to locate other items associated with it.

The names of selected cities and waters are designed in such a way that the readability is maintained at the smallest possible size so as not to obscure the image area too much and not to detract from the presented landscape. It was noted that the white and gray are the colors most neutral and least aggravating the picture. After numerous attempts Calibri in white, with black shadow was selected.

Apart from cities and waters with their names a cartographic grid is placed on the map to serve as an additional reference. Beyond the longitude and latitude it is information about the applied cartographic projection. It was assumed that the grid would be readable, but barely visible, so as not to attract attention.

The data sources on drainage, water bodies and settlements are listed in the "Appendix" chapter.

\section{Result}

According to the developed procedure, the elevation data of SRTM30 were visualized in a form of a map of Europe at scale of 1:10 million. The map design is not typical. It is more a scientific visualization of data in a map form than a map itself. The water bodies in the background are shown in light blue color specially chosen for good contrast, and the lands in the foreground are represented in shades of green and beige, according to the true colors of the Earth recorded by MODIS. A combination of the Earth's surface colors and slightly exaggerated terrain features makes a realistic map showing the landscapes as if from a point above the Earth. One can see mountains and valleys, plateaus and plains, densely vegetated areas and deserts.

The shape of the terrain is depicted with the use of a combined shaded relief method which manifests itself in two ways. Firstly as an oblique shading, meaning that North-West slopes are considered illuminated by the artificial light source and, thus, they are visible as brighter than the others. This phenomenon makes an illusion of three-dimensionality and the mountains look raised on the map. Secondly, as a slope shading, which makes the steeper slopes darker, and in effect the mountains look darker on the map than the plains. This way of visualization exposes relative heights of the terrain and differentiates graphically various mountain systems. It is clearly noticeable that some systems consists of continuous mountain chains when the other looks like a group of separate mountains.

There are several sub-areas on the map that can be delimited as regions because of their graphical uniformity. Such uniformity is not accidental and indicates some kind of uniformity in the real world because in this objective compilation all the data were treated the same way in the applied procedure. The legend does not exist and the meaning of each homogeneous region noticed on the map can only be interpreted by the user himself. This property of the map enables one to show the real look of the Earth's surface as it is, with more dynamic changes of relief and rather smoothly changing vegetated areas.

The image of the terrain looks sharp and detailed and there is hardly a place without at least a slight 
change in shade or color. It can be explained as follows. At the scale of 1:10 million a good quality picture of the terrain can be made from data defined for each square $\mathrm{km}$ ( $1 \mathrm{~km}$ ground resolution). This follows from the equation $(10,000,000 \times 0.1 \mathrm{~mm}$ $=1 \mathrm{~km}$ ) in which $0.1 \mathrm{~mm}$ is the smallest, visible point of the image. The other solution would be to repeat each picture element twice or thrice thus using less data or data with lower ground resolution, but then the image would be blurred. In this case the condition of good quality image is met because the shaded relief images of SRTM30 elevation data with resolution of $1 \mathrm{~km}$ are used without any resampling. In the result, the image of the terrain is extremely detailed as it is based on the abundance of data defining the elevation of each point of land represented on the map.

Azimuthal equidistant projection was selected with the central point coordinates $\varphi=50^{\circ}, \lambda=20^{\circ}$ having the advantage that all the distances from a central point to any point on the map are represented at the scale of the map. The area covered by the map was defined so that it covers the whole of Europe and the North Pole. To make a map of this extent in the assumed projection, the following geographic coverage for both types of data had to be prepared: in latitude from $\varphi=20^{\circ} \mathrm{N}$ to $\varphi=90^{\circ} \mathrm{N}$ and in longitude from $\lambda=90^{\circ} \mathrm{W}$ to $\lambda=130^{\circ} \mathrm{E}$. According to the design, the reference content of the map was added in the form of waters and cities with their names, the grid for multiples of $10^{\circ}$ and finally the geographic lines of the Tropic of Cancer and the Arctic Circle. A frame with a description of latitude and longitude and the map title was also added. Figure 8 shows the final result: in overview on the left side and a little enlarged fragment on the right.

\section{Conclusions}

The presented research project resulted in combined visualization of SRTM and MODIS data not viewed earlier in this way. The small-scale, realistic image of the Earth's surface with sharp detail, simulates the view from high altitude (as if from the deck of a spacecraft). The image is photo-realistic, however, it emerged not in a natural way but synthetically by combining shaded relief with a color image of the terrain. The result recalls the image of the world from the Hal Shelton maps because roughly the same range of colors is used in a similar way to depict vegetation and similarly exaggerated are landform features, which in reality can not be seen so clearly from a great height. The main difference is, however, that such visualization is based on actual data. By the slight exaggeration of landform features the image of the terrain is to some extent explained because the relationship between vegetation and relief is obvious.

This visualization can be considered as the new form of a physical map. The purpose of the map is to show users the actual appearance of the Earth's surface and perpetuate this vision as an image of the world around them. Such a map as any reference map, contributes to the basic need of orientation in space and provides a reference for spatial information. It meets the intent of the modern small-scale reference maps by giving the evocative image of the area. This property is a condition sine qua non for enabling the observer to penetrate the area using his own imagination and to understand it by considering spatial relationships of individual elements of the landscape. This type of a map is in some sense "alive" as it represents the source data without imposing their interpretation. According to MACEACHREN (2004), maps neither contain the message nor communicate it to users, but stimulate ideas and proposals through the interaction with the knowledge already owned by them. This opinion can be considered a good alibi for the map, which only shows the two main factors affecting the landscape-vegetation and relief, without subjectively designated limits.

The developed map of Europe is an objective compilation of data recorded by the specialized satellite instruments, which makes this map different from many other maps being made currently. As a result, the world on the map is more closely tied to the real world and the interpretations of this map are rooted in reality. As it was described in the paper, the information contained in the SRTM data was successfully revealed with the method based on combined shaded relief. This information concerns all the land represented on the map so we can see 
both the steep mountains of the Alps and the hilly areas, cut by rivers in the landscape of Ukraine. This depiction of the Earth's surface is innovative and could be produced only because such detailed data were available and the work on developing the method were successful. It is also instructive and inspiring as it reveals many geographic features showing the landforms in detail or simply showing them in another way visually (LoveLock 2010).

It may be regarded as better than a "classic" physical map with hypsometric tints because its look is realistic, not abstract; it shows landscapes made by a combination of relief and vegetation instead of elevations only, and, finally, it shows the terrain in detail. On the other hand, the original SRTM elevation data are too detailed for hypsometric tinting maps (LeONOwicZ and JenNy 2011). Also it may be regarded as better than the Earth's surface depictions of contemporary cartographers who focus more on cartographic standards than on unprecedented geospatial data they deal with. A compulsion to explain the map in the map legend prevents them from using MODIS continuous image of vegetation because this image is not showing separate categories of land cover. As a result, their new physical maps are actually land cover maps based on "arbitrary" classification of satellite imageries with elevation data put to the background (Patterson and Jenny 2011). But even so the elevation data displayed together with numerous land cover classes produce an image, which is visually heavy and complex (PATTERson and KeLso 2004).

Using the trial and error method to reach the best solution of presenting elevation data graphically, an original version of combined shading was find out. With experimentally defined parameters of oblique and slope shading, the developed version appeared to be advantageous not only by properly depicting relief but also by making successful fusion with the color image. The map of Europe shows relief with all its irregularities which can be interesting for researchers. Among all examined methods of representing elevation data in a graphic form one, could hardly find a solution imitating reality. There are strictly cartographic modifications of the two leading methods: hypsometric tinting and shaded relief, which show the Earth's surface in apparently artificial colors.
Photo-realistic depictions of the Earth's surface have at least one common characteristic: it is impossible to construct a legend explaining the meaning of each color. However, it is unavoidable since the image of the Earth's surface is precisely this (or rather the same type), and such is its modelled imitation presented here.

Despite apparent photo-realism, the image is created artificially according to applied graphic design. The terrain topography is highlighted by relief shading techniques with the light source falsely located in the northwest to make a successful impression of three-dimensionality. There are no cast shadows and the blue atmospheric haze does not distort actual colors of the Earth's surface. A specific approach was applied to reference elements locating the image of the Earth's surface in geographic space. They are almost invisible at first glance and do not interfere with the picture of the whole area. This leads the observer above all to see and remember a unique view of the landscape from a height, which is the intended effect.

The way of presenting the world on maps can be treated after Montello (2002), with great respect, as the maps being "tools" to explore the world are shaping not only our mental maps, but also in some sense, our psychological structures of accumulation of knowledge and views of the surrounding reality. It follows that there is a great role for small-scale popular maps, reaching the greatest number of customers. Therefore, creating new images of the world and showing the world in a new way makes sense, especially when it is close to the true image of the Earth. After all, realistic images of the Earth's surface are a valuable complement to the materials and methods of teaching geography at all levels. In previous years these materials were simply not available.

\section{Acknowledgments}

This paper is based on the research conducted in the project No. N N526 193636 financed by the Polish Ministry of Science and Higher Education in years 2009-2012. The MODIS imagery has been downloaded from "a catalogue of NASA images and 
animations of our home planet" http://visibleearth. nasa.gov/. SRTM data were downloaded from NASA page http://dds.cr.usgs.gov/srtm/.

Open Access This article is distributed under the terms of the Creative Commons Attribution License which permits any use, distribution, and reproduction in any medium, provided the original author(s) and the source are credited.

\section{Appendix}

\section{Web Pages Relevant to the Subject}

1. Virtual terrain project (http://vterrain.org/Imagery/ WholeEarth/).

2. Nasa Earth observatory (http://earthobservatory. nasa.gov/Features/BlueMarble/

BlueMarble_monthlies.php).

3. GL stock images (http://graphicleftovers.com/ graphic/washington-shaded-relief-map/).

\section{Information on Drainage and Water Bodies}

1. 10m_rivers_lake_centerlines (http://www.natural earthdata.com/).

2. GSHHS: a global self-consistent, hierarchical, high-resolution shoreline database.

3. WDBII: the CIA world data bank II.

\section{Information on Settlements}

1. Urban area: areas of cities with the English name and information about the level of detail (1:10 million map) (http://www.naturalearthdata.com/)

2. Cities: points with the English name and the assigned population class. A set of ESRI data (Europa_dane_esri_SHP \basemap).

3. Urban areas: polygons of cities with the English name and information about the area $\left(\mathrm{km}^{2}\right)$, no attribute of a population a collection of ESRI (Europa_dane_esri_SHP \basemap).

4. Urban morphological zones: polygons of cities within the European Union. A collection developed based on Corine classification of 1990 (http://www. eea.europa.eu/data-and-maps/data/urban-morpholo gical-zones-1990-umz90-f1v0).
5. Global maps of urban extent from satellite data: resulting bitmap, time-spectral classification of MODIS imageries from the years 2001-2002 with a resolution of $500 \mathrm{~m}$ (http://sage.wisc.edu/maps datamodels.html) (SCHNEIDER et al. 2010).

\section{REFERENCES}

Bamler, R., (1999), The SRTM Mission: A World-Wide $30 \mathrm{~m}$ Resolution DEM from SAR Interferometry in 11 Days, Photogrammetric Week '99, Wichmann Verlag, Heidelberg, 1999.

CRIPPEN R. E., (2010), Global topographical exploration and analysis with the SRTM and ASTER elevation models, Geological Society, London, Special Publications 2010; v. 345; p. 5-15.

Drachal J., (1987), Optymalna metoda wizualizacji obrazu cyfrowego, Prace Instytutu Geodezji i Kartografii, Tom XXXIV, zeszyt 2(79), 13-32.

Drachal J., (1994), Zwiększenie rozdzielczości obrazu barwnego w wyniku syntezy z panchromatycznym obrazem czarno-białym o wyższej rozdzielczości, Prace Instytutu Geodezji i Kartografii, Tom XLI, zeszyt 89, 131-140.

Farr, T.G., E. Caro, R. Crippen, R. Duren, S. Hensley, M. Kobrick, M. Paller, E. Rodriguez, P. Rosen, L. Roth, D. Seal, S. Shaffer, J. Shimada, J. Umland, M. Werner, M. Oskin, D. Burbank, D. Alsdorf, (2007), The Shuttle Radar Topography Mission, v. 45, Reviews of Geophysics.

GuTH P., L., (2006), Geomorphometry from SRTM: Comparison to NED, Photogrammetric Engineering \& Remote Sensing, Vol. 72, No. 3, March 2006, pp. 269-277.

Iмноғ, Е. (1982). Cartographic Relief Presentation. New York and Berlin: Walter de Gruyter.

Jenny B., Rabe. S., (2006) http://www.reliefshading.com/.

Keates J. S., Cartographic Design and production (Longman, London 1973).

Kennelly P., J., (2008), Terrain maps displaying hill-shading with curvature, Geomorphology 102 (3-4), p. 567-577.

Leonowicz A. M., Jenny B., (2011) Generalizing digital elevation models for small scale hypsometric tinting, Zurich Open Repository and Archive, University of Zurich, http://dx.doi.org/ 10.5167/uzh-52942.

Lovelock J., (2010), Visualizing the land surface, http://www .sagepub.com/upm-data/32897_01_Gregory_CH_01.pdf.

MacEachren, A., (2004). How Maps Work: Representation, Visualization, and Design. Guilford Press.

MedyŃSKA-Gulis B., (2011). Kartografia i geowizualizacja. Wydawnictwo Naukowe PWN SA, Warszawa.

MichalaK J., (2003), DEM Data Obtained from the Shuttle Radar Topography Mission - SRTM-3, http://netgis.geo.uw.edu.pl/ srtm/JM-SRTM3.pdf.

Montello D., (2002), Cognitive map-design research in the twentieth century: Theoretical and empirical approaches. Cartography and Geographic Information Science, vol. 29, No. 3, 283-304.

Patterson, T., Jenny, B. (2011). The development and rationale of cross-blended hypsometric tints. Cartographic Perspectives 69, p. 31-45. 
Patterson T., Hermann M.,(2004). Creating value-enhanced shaded relief in Photoshop, http://www.shadedrelief.com/value/ value.html.

Patterson T., Retro Relief Shading, http://www.shadedrelief.com/ retro/index.html.

Patterson T., Kelso N., (2004), Hal Shelton Revisited: Designing and Producing Natural-Color Maps with Satellite Land Cover Data, Cartographic Perspectives 47, 28-55, 69-80.
Patterson T., (2002), Getting Real: Reflecting on the New Look of National Park Service Maps, Cartographic Perspectives 43, 43-56.

Schneider A., Friedl M., Potere D., (2010), Monitoring urban areas globally using MODIS $500 \mathrm{~m}$ data: New methods and datasets based on 'urban ecoregions, Remote Sensing of Environment, vol. 114, 1733-1746.

(Received July 31, 2012, revised May 2, 2013, accepted May 3, 2013, Published online May 22, 2013) 